\title{
VIEWPOINT
}

\section{Integrated biochar research: A roadmap}

James E. Amonette, Humberto Blanco-Canqui, Chuck Hassebrook, David A. Laird, Rattan Lal, Johannes Lehmann, and Deborah Page-Dumroese

A scientific consensus is building that the drawdown of very large amounts (at least $1,000 \mathrm{Gt}[1.1 \times$ $\left.\left.10^{12} \mathrm{tn}\right]\right)$ of carbon dioxide $\left(\mathrm{CO}_{2}\right)$ from the atmosphere will be needed to stabilize the earth's climate system at a safe temperature (Hansen et al. 2008; Cao and Caldeira 2010; IPCC 2018, 2019). The minimum estimated cost of this drawdown is tens of trillions of dollars over the course of a century and ultimately will depend on the total amount of fossil carbon (C) emitted by humankind (emissions must be reduced as quickly as possible to make any drawdown effective). The cost of drawdown, while high, is a bargain when compared to the cost of unabated climate change.

In response to this consensus, a variety of $\mathrm{CO}_{2}$-drawdown approaches have been suggested, including, among others, direct air capture, afforestation and reforestation, enhanced weathering of silicate minerals, changes in land management practices to increase stocks of soil organic C, and thermal conversion of biomass to bioenergy coupled with storage of the biochar $\mathrm{C}$ formed in the process (Smith et al. 2015; Smith 2016). All these approaches will be needed in a successful drawdown effort. All will need the development of policies to support their implementation. Additionally, to reach their full potential, all will require substantial funding for research to resolve remaining technical issues and explore deployment and drawdown synergies among them.

Here, we provide the rationale and broad outline for a long-term integrated research program that focuses on biochar, a relatively persistent solid form of $\mathrm{C}$ produced by thermal conversion of biomass under low-oxygen $\left(\mathrm{O}_{2}\right)$ conditions. Biochar can be stored in a number of ways to sequester the C (e.g., in concrete and asphalt), but when added to soil it persists with a mean residence time measured in centuries and may provide beneficial services including enhanced vegetative productivity and diminished emissions of nitrous oxide $\left(\mathrm{N}_{2} \mathrm{O}\right)$, among many others (Lehmann et al. 2006; Laird 2008; Laird et al. 2009; Woolf et al. 2010, 2014, 2016; Lehmann and Joseph 2015; Jeffery et al. 2015; Borchard et al. 2019). In addition to these climate-related benefits, the deployment of biochar-based technology can combat land degradation and improve soil health (Spokas et al. 2012), reduce nutrient leaching (Borchard et al. 2019), increase water storage (Blanco-Canqui 2017; Kroeger et al. 2020), improve livestock health and productivity (Kammann et al. 2017; Schmidt et al. 2019; Man et al. 2020), enhance food security (Lal 2009, 2020) and decrease the risk of wildfire (thereby improving forest health, air quality, and human health) (Pollet and Omi 2002; Sahoo et al. 2019; Sarauer et al. 2019; Sessions et al. 2019). Further, growing/harvesting the feedstock, converting it to biochar and bioenergy, and applying the biochar to cropped and forested lands, can provide a strong boost to rural economies, particularly if ways can be found to monetize the many indirect benefits listed above. Recent economic analyses suggest that deployment of a biochar/bioenergy platform would be most successful in the Southeast region of the United States where crop yields would increase the most and woody biomass is readily available ( $\mathrm{Li}$ et al. 2019; Dumortier et al. 2020).

The scientific literature reveals a wide range in the estimated technical potential of biochar as a $\mathrm{CO}_{2}$-drawdown strategy (IPCC 2019). A large part of this variability stems from different assumptions about the amount of biomass available. Additional variability arises from consideration of (1) the different production methods that can be used and the degree to which the energy released during production is captured and used to offset fossil-based sources, (2) the types and qualities of biochar that can be made, and (3) the biophysical responses of soils and the cropping systems to which biochar is applied. An idea of the maximum

Received November 15, 2020.

C-drawdown potential may be obtained from the data of Woolf et al. (2010), who estimated that, with annual conversion of $2.3 \mathrm{Gt}\left(2.5 \times 10^{9} \mathrm{tn}\right) \mathrm{C}$ in sustainably procured biomass, $6.6 \mathrm{Gt} \mathrm{CO}_{2} \mathrm{eq} \mathrm{y}^{-1}(7.3$ $\times 10^{9}$ tn $\mathrm{CO}_{2}$ eq $\mathrm{yr}^{-1}$ ) in avoided emissions could be achieved at full production, half of which are due to biochar-C stored in soil. The maximum sustainable C-drawdown potential of biochar technology thus is about $3.3 \mathrm{Gt} \mathrm{CO}_{2} \mathrm{y}^{-1}$ (3.6 $\times 10^{9}$ tn $\mathrm{CO}_{2} \mathrm{yr}^{-1}$ ) and, over the course of a century, could account for a third of the $1,000 \mathrm{Gt}\left(1.1 \times 10^{12} \mathrm{tn}\right) \mathrm{CO}_{2}$ that needs to be removed from the atmosphere.

The exponential growth in the biochar scientific literature (Wu et al. 2019) during the past two decades has expanded our knowledge of the potential impact of biochar on vegetative productivity and mitigation of climate change. Nevertheless, the fast pace of development, the diversity of feedstocks, biochar production methods, and responses by agricultural, horticultural, silvicultural and rangeland systems, coupled with short funding cycles and the lack of a comprehensive coordi-

James E. Amonette is a senior research geochemist in the Physical Sciences Division, $\mathrm{Pa}$ cific Northwest National Laboratory, Richland, Washington, and a research professor of soil chemistry, Center for Sustaining Agriculture and Natural Resources, Washington State University, Richland, Washington. Humberto Blanco-Canqui is a professor of soil science in the Department of Agronomy and Horticulture, University of Nebraska, Lincoln, Nebraska. Chuck Hassebrook is the vice-president for project development at Sandhills Energy LLC, Lincoln, Nebraska. David A. Laird is professor emeritus of agronomy in the Department of Agronomy, lowa State University, Ames, lowa, and president of N-Sense LLC, Ames, lowa. Rattan Lal is distinguished university professor of soil science and director of the Carbon Management and Sequestration Center, The Ohio State University, Columbus, Ohio. Johannes Lehmann is Liberty Hyde Bailey professor of soil and crop sciences in the School of Integrative Plant Science, Cornell University, Ithaca, New York. Deborah Page-Dumroese is a research soil scientist at the Rocky Mountain Research Station, United States Forest Service, Moscow, Idaho. 
nated approach, have left significant gaps in this knowledge base. These knowledge gaps have generated a need for coordinated, large-scale, regionally focused, long-term studies of biochar production and application to answer questions about the technology's cost and potential impact, and to guide future development.

\section{FOUNDATIONAL SCIENCE FOR BIOCHAR IMPLEMENTATION}

Several recent workshops have identified biochar research and development priorities (Jeffery et al. 2015; Kammann et al. 2017; Tammeorg et al. 2017; Amonette et al. forthcoming). The most recent of these workshops (Amonette et al. forthcoming) recommended the creation of a long-term coordinated research and development program to provide the foundational science needed to support three closely related efforts focused on near-term technology development, business support, and collaborative policy development. These efforts would be guided by interactions with the public and commercial sectors. We adopt this overall framework (figure 1) and, following the approach suggested by Jeffery et al. (2015), we suggest that the foundational scientific research effort be organized into the following two categories:

- Mechanistic research that focuses on the fundamental processes controlling (1) thermochemical conversion efficiency and (2) biochar performance across a variety of soils, plant communities, and climatic zones using a standard set of biochars representing common feedstocks and conversion processes.

- Systems-oriented research focused on (1) testing of pilot-scale thermochemical conversion methods using local feedstocks, (2) site-specific applications of biochar coupled with measurement of relevant biophysical system responses, and (3) the performance of full life-cycle and techno-economic analyses with the objective of refining promising systems for production and use of biochar in agriculture, forestry, and horticulture within the region where the site is located.

Consolidation and integration of information gathered under these two research

\section{Figure 1}

Overview of the development pathway for biochar technology. The foundational role played by the proposed long-term integrated research program is shown at bottom in red.

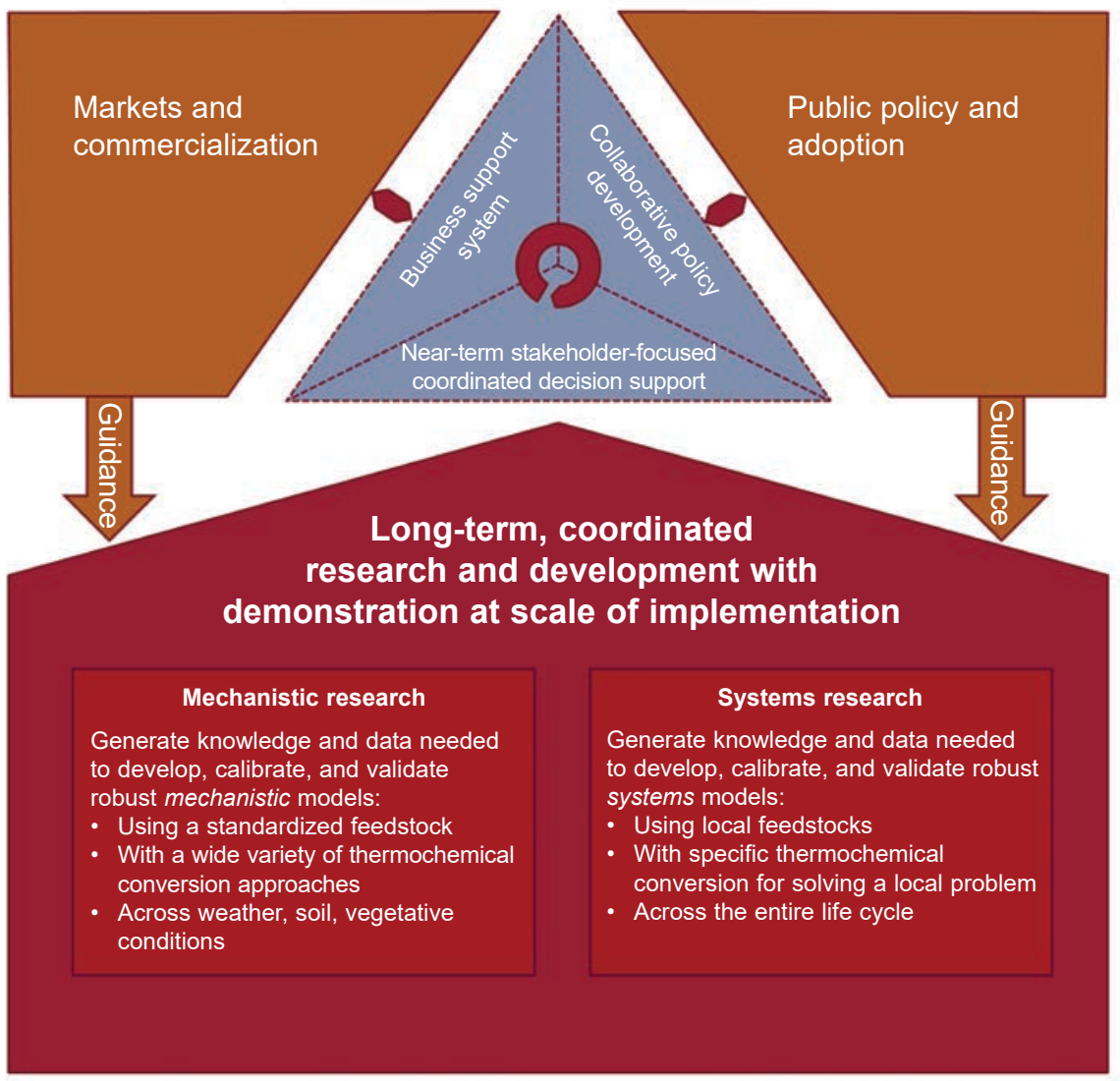

categories would be accomplished by developing, calibrating, and validating robust predictive models. In addition to improving fundamental models of pyrolysis and reactor design, this effort would enhance the capacity of existing biochar soil models to predict future behavior of biochar-amended soils and would include, as key output variables, measures of soil health (e.g., soil organic C content and stock, soil $\mathrm{pH}$, water-holding capacity, aggregation, water infiltration rate, and biological properties [Bünemann et al. 2018; Lehmann et al. 2020]), biomass/cropping yields, farm/ranch profitability, greenhouse gas emissions, and losses of biochar due to oxidation to $\mathrm{CO}_{2}$ and erosion.

The integrated research program we propose would nominally involve as many as 20 research sites. While the exact number and configuration of research sites depend on a variety of factors, roughly a third of them would focus on agronomic cropping systems (dryland and irrigated), a third on forest and rangeland systems, and the remainder on compost and manure management, horticulture, turf, urban, and the built environment. One "site" would perform the integrative modeling function and thus would not necessarily be a single geographic location.

Below we provide further details of the experimental framework for the agronomic, forestry, and rangeland portions of this program.

\section{MECHANISTIC RESEARCH}

This research would generate knowledge and data needed to develop, calibrate, and validate models that provide mechanistic insights on thermochemical conversion processes, as well as climate, soil, or management effects on biochar mineralization, 
priming of soil organic C, plant growth, and soil greenhouse gas emissions.

Thermochemical Conversion Efficiency. Work on this topic would focus on the fundamental aspects of pyrolysis and gasification with an aim to improve understanding of the interactions of feedstock properties (type, particle size, moisture content) and reactor conditions (temperature, residence time, $\mathrm{O}_{2}$ levels) on the relative proportions of biochar, bio-oil, and syngas product streams. Mechanistic descriptions of the fundamental phenomena occurring during pyrolysis (heat transfer, mass transfer, chemical reactions, and phase changes), how they interact, and how they scale in going from single particles to full biorefineries would be a major focus of this work (Pecha et al. 2019). These descriptions would be incorporated into process and techno-economic models to help guide design of new, more-efficient biochar (and bioenergy) production reactors and biorefineries.

Processes Controlling Biochar Performance. Field experiments would assess the performance of a standard set of well-characterized biochars that would be deployed at all study sites. A strategic approach would be taken to utilize biochars produced by all the production technologies that have broad applicability (fast pyrolysis, slow pyrolysis, gasification) in combination with major feedstocks representing important biogeochemical differences (ash composition and content, lignin content, cellulose content). Thus, a minimum of nine biochars representing the major feedstock types (e.g., wood, straw, and manure) and production methods would be used. This standard set could be expanded substantially by the addition of biochars produced at different reaction temperatures or activated by different processes after production.

The main thrusts of the mechanistic field studies would be to

- identify broad cross-site correlations among key site parameters (e.g., climate, soil type, water regimes, application technologies, and soil-management regimes), key biochar chemical and physical properties, and biochar performance in soils (e.g., greenhouse gas exchange, plant growth, soil loss by leaching and erosion);

- identify and parameterize the biophysical mechanisms responsible for these correlations; and

- develop algorithms to represent these mechanisms and the resulting response functions and incorporate them into soil biochar predictive models.

Because of the emphasis on developing mechanistic insight, many of the experimental field plots can be smaller than those in systems-oriented experiments. Consequently, full use will be made of small plots and core samples in addition to the large field-scale plots needed to assess plant responses. Plots on range sites would be similar in size to the agronomic plots, but forest plots might be larger, depending on site characteristics. Ample replication would be utilized to refine response functions.

\section{SYSTEMS-ORIENTED RESEARCH}

This research would provide new knowledge to refine the most promising biochar strategies in each of the site locations that would contribute to farm and ranch productivity/profitability, greenhouse gas reductions, atmospheric $\mathrm{CO}_{2}$ removal, and other environmental objectives, including but not limited to water and air quality.

Thermochemical Conversion Using Local Feedstocks. For each site, local feedstocks would be used to make biochar by the most appropriate production approach (slow pyrolysis, fast pyrolysis, gasification, or a combination thereof). The main point of these production tests would be to establish the economic viability, energy efficiency, C partitioning, and net emissions data needed to identify the best $\operatorname{method}(\mathrm{s})$ for the feedstocks available in a given region. The production equipment would not necessarily be located at the site from which the feedstock is obtained or where the biochar is tested-it likely would be more economical (for research purposes) to have a few sites where all biochar production is done, with transport of feedstock and biochar between the regional sites where biochar testing occurs. The criteria for siting the different biomass-conversion technologies would ensure that
- sufficient biochar from local feedstocks is provided for regional experimentation and demonstration, and

- full engineering data on mass, economic, energy, and emission balances for the systems analyses can be obtained. Because the main purpose would be to produce the biochar for field experiments at a scale sufficient to provide reasonable life-cycle assessments, pilot-scale facilities (ca. 1 to $10 \mathrm{t} \mathrm{d}^{-1}$ [1.1 to 11 tn day $^{-1}$ ) would be used when possible. Large-scale wood gasifiers used to generate bioenergy, however, are relatively common and currently provide the majority of the biochar sold in the United States. Consequently, one of these full-scale facilities would be used to produce a standard wood biochar made from the same feedstock to help calibrate results across the regional sites.

Site-Specific Measurement of Biophysical System Responses. The systems-oriented field experiments would explore interactions among biochar type, biochar application rate, and fertilization rate (as appropriate), and their impact on vegetative productivity, environmental parameters, and farm/ranch profitability, for the ecosystem(s) at each site. These experiments also would include studies that account for regional differences. Examples include site-specific biochar types, water regimes, application technologies, biochar-activation technologies, and cropping systems. Experiment selection at each site would be determined by local needs and expertise yet guided by the underlying principles and measurement regimes of the overall research program. Full field-scale operations with farm or forestry equipment would be utilized with sufficient replication to allow unambiguous testing of the plant, environmental, and economic responses at the scale of implementation. As in the mechanistic research, plots on range sites would be similar in size to the agronomic plots, but forest plots might be larger, depending on site characteristics. Full randomization and appropriate systems-level comparisons to business-as-usual would be included.

Life-Cycle and Techno-Economic Assessments. The detailed, site-specific knowledge and data generated during biochar-production activities and 
field experimentation would be used to develop, calibrate, and validate robust systems models that

- address biochar production issues as well as soil-crop-climate-management-biochar interactions, and

- predict plant-response, environmental, and economic outcomes for specific implementations of biochar technology using full life-cycle and techno-economic assessment approaches.

To achieve this goal, the systems-oriented experiments would be designed to specifically address knowledge gaps that are currently limiting these models.

\section{PROGRAM SUMMARY, EXPECTED RESULTS, AND ESTIMATED COST}

The ambitious program of research we have outlined above addresses several key issues faced by humanity in the 21st century including climate change, economic viability of rural communities, wildfire hazards, and the health of ecosystems, humans, and livestock (table 1). Given the urgency of the climate crisis, we contend that a coordinated long-term multisite program offers the fastest and most cost-effective way to obtain the scientific, technical, and economic knowledge needed to critically assess and guide implementation of biochar technology. We need to optimize biochar-production technologies, and to develop a better understanding of the longevity of the full range of biochar types in soil under widely varying environmental and management conditions, and of the long-term impact of biochar on vegetation composition and crop quality, native soil organic $\mathrm{C}$ stocks, non- $\mathrm{CO}_{2}$ greenhouse gas emissions, and many other soil processes. Variability associated with different feedstocks; soil types; and climate, water, and management regimes often is too high to allow accurate predictions of biochar behavior and impact to be made for specific locations.

Our approach (figure 2) involves the coordination of research across about 20 field sites, which will allow for cross-site mechanistic studies using standard biochars, experimental protocols, and measurements while at the same time giving flexibility for companion systems-oriented studies to

\section{Table 1}

Summary of societal needs potentially addressed by biochar technology, current knowledge gaps, proposed research approach, and expected results.

\begin{tabular}{ll}
\hline Parameters & Values \\
\hline Societal needs & Removal of $\geq 1,000$ Gt carbon dioxide from the atmosphere \\
& Revitalization of rural economies \\
& Reduction in wildfire risk \\
Improved health of soils, forests, humans, livestock \\
Knowledge gaps & Long-term persistence of biochar carbon in soils \\
& Long-term yield responses of vegetation to biochar amendments \\
& Optimal biochar production methods \\
& Impact of biochar on native carbon stocks in soil \\
& Mechanisms responsible for biochar impact on soil greenhouse gas \\
& emissions \\
& Variability associated with feedstock, climate, soil, water, management \\
& Potential synergies with other negative emission technologies \\
& Long-term studies \\
& Regionally focused ( 20 field sites) \\
Research approach-site mechanistic studies on biochar production and performance & Systems-oriented studies with local feedstocks, biochars, vegetation \\
& Knowledge consolidation in pyrolysis, soil-biochar, life cycle assessments, \\
& and techno-economic models \\
& Validation of biochar carbon drawdown potential \\
Identification of best biochar technology practices at regional level \\
Quantification of potential economic impacts of biochar technology \\
Firm scientific foundation for new industry \\
Education of students and bio-economy stakeholders
\end{tabular}

address local problems and opportunities for productive use of biochar. We propose initiating field experiments in three stages with each successive stage being informed by interpretation of the results gained in the previous stage. The data generated will be consolidated in a suite of models that range from fundamental pyrolysis-chemistry and mechanistic soil-biochar models to more systems-oriented plant-response models, and life-cycle and techno-economic assessments.

Expected Results. Data produced by this program will help define the best approaches for making and using biochar with respect to net economic returns, economic impacts on rural communities, and climate-change mitigation. We expect the further improvement of site-specific models of plant responses to biochar amendments, based on the fundamental understanding of biochar production and soil-biochar interactions, will significantly lower the economic risks associated with implementation of biochar technology and increase the potential returns. Furthermore, the understanding of how to use biochar to reduce greenhouse gas emissions and increase soil $\mathrm{C}$ sequestration will facilitate payments to land managers for ecosystem services. These benefits should, in turn, lead to more profitable ventures for biochar producers, higher returns for primary agricultural and silvicultural producers, and steady, long-term support for rural economies. With respect to climate, we expect the results of this program will include a substantial improvement in our ability to estimate the C-drawdown potentials of the many possible implementations of biochar technology. These will inform public and private policy, facilitate monetization of climate benefits, and help direct the appropriate level of resources to development of the industry. The results will also provide a foundation for exploration of potential synergetic interactions of biochar with other land-based negativeemission technologies.

The program would make full use of university, federal, state, local, and commercial expertise in a variety of technical fields associated with biochar technology. Further, it would train a new cadre of students, farmers, foresters, landscape designers, and homeowners, among oth- 


\section{Figure 2}

Concept of activities and information flow during proposed long-term integrated biochar research program. Details of Stages 2 and 3 are similar to those shown for Stage 1. "Expts" signifies experiments.

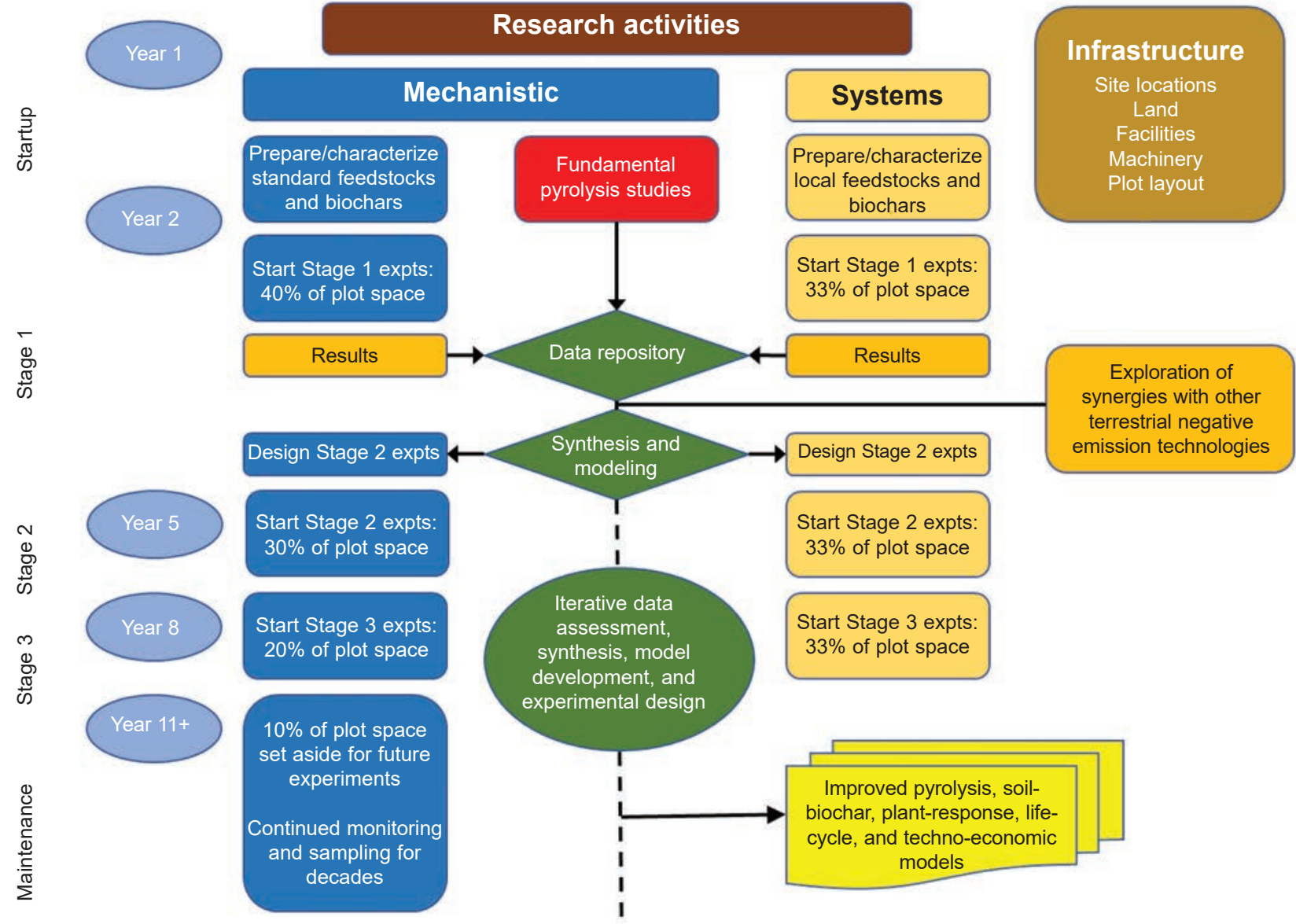

ers, to help tackle the major challenges associated with mitigation and adaption to climate change.

Estimated Cost. We estimate that the program will have a total annual cost of approximately US\$150 million. Funding would continue at this level for a decade, during which time most of the short-term questions related to biochar technology could be answered; thereafter, funding would decrease to the level required to maintain sampling and analysis of the long-term experiments into the future.

\section{CONCLUDING REMARKS}

The time to define and implement solutions to address the peril of climate change is now. We believe that investment in this integrated long-term research program would, within a decade, resolve the most important information needs with respect to the technology for biochar and bioenergy production and the agronomic and environmental impacts of biochar use. This information is critically needed by both private and governmental decision makers to ensure that deployment will yield the maximum productivity, economic, and environmental benefits. Biochar and integrated biochar-bioenergy production systems have the potential to become a robust distributed industry supporting rural economies and an important part of a broader portfolio of solutions to climate change. All will be needed to meet the challenge.

\section{REFERENCES}

Amonette, J.E., J.G. Archuleta, M.R. Fuchs, K.M. Hills, G.G. Yorgey, et al. Forthcoming. Biomass to Biochar: Maximizing the Carbon Value. Workshop Report. Pullman, WA: Center for
Sustaining Agriculture and Natural Resources, Washington State University. http://csanr.wsu. edu/biomass2biochar.

Blanco-Canqui, H. 2017. Biochar and soil physical properties. Soil Science Society of America Journal 81:687-711.

Borchard, N., M. Schirrmann, M.L. Cayuela, C. Kammann, N. Wrage-Mönnig, J.M. Estavillo, T. Fuertes-Mendizábal, G. Sigua, K. Spokas, J.A. Ippolito, and J. Novak. 2019. Biochar, soil and land-use interactions that reduce nitrate leaching and $\mathrm{N}_{2} \mathrm{O}$ emissions: A meta-analysis. Science of the Total Environment 651:2354-2364.

Bünemann, E.K., G. Bongiorno, Z. Bai, R.E. Creamer, G. De Deyn, R. de Goede, L. Fleskens, V. Geissen, T.W. Kuyper, P. Mäder, M. Pulleman, W. Sukkel, J.W. van Groenigen, and L. Brussaard. 2018. Soil quality—A critical review. Soil Biology and Biochemistry 120:105-125.

Cao, L., and K. Caldeira. 2010. Atmospheric carbon dioxide removal: Long-term consequences and 
commitment. Environmental Research Letters 5:024011.

Dumortier, J., H. Dokoohaki, A. Elobeid, D.J. Hayes, D. Laird, and F.E. Miguez. 2020. Global land-use and carbon emission implications from biochar application to cropland in the United States. Journal of Cleaner Production 258:120684.

Hansen, J., M. Sato, P. Kharecha, D. Beerling, R. Berner, V. Masson-Delmotte, M. Pagani, M. Raymo, D.L. Royer, and J.C. Zachos. 2008. Target atmospheric $\mathrm{CO}_{2}$ : Where should humanity aim? Open Atmospheric Science Journal 2:217-231.

IPCC (Intergovernmental Panel on Climate Change). 2018. Special Report: Global Warming of $1.5^{\circ} \mathrm{C}$. Geneva, Switzerland: Intergovernmental Panel on Climate Change. https://www.ipcc.ch/sr15/.

IPCC (Intergovernmental Panel on Climate Change). 2019. Special Report: Climate Change and Land. Geneva, Switzerland: Intergovernmental Panel on Climate Change. https://www.ipcc.ch/srccl/.

Jeffery S., T.M. Bezemer, G. Cornelissen,T.W. Kuyper, J. Lehmann, L. Mommer, S.P. Sohi, T.F.J. Van de Voorde, D.A. Wardle, J.W. Van Groenigen. 2015. The way forward in biochar research: Targeting trade-offs between the potential wins. Global Change Biology Bioenergy 7:1-13.

Kammann, C., J. Ippolito, N. Hagemann, N. Borchard, M.L. Cayuela, J.M. Estavillo, T. Fuertes-Mendizabal, S. Jeffery, J. Kern, J. Novak, D. Rasse, S. Saarnio, H.-P. Schmidt, K. Spokas, and N. Wrage-Mönnig. 2017. Biochar as a tool to reduce the agricultural greenhouse-gas burden - knowns, unknowns and future research needs. Journal of Environmental Engineering and Landscape Management 25(2):114-139.

Kroeger, J.E., G. Pourhashem, K.B. Medlock, and C.A. Masiello. 2020. Water cost savings from soil biochar amendment: A spatial analysis. Global Change Biology Bioenergy 13(1):133-142.

Laird, D.A. 2008. The charcoal vision:A win-win-win scenario for simultaneously producing bioenergy, permanently sequestering carbon, while improving soil and water quality. Agronomy Journal 100:178-181.

Laird, D.A., R.C. Brown, J.E. Amonette, and J. Lehmann. 2009. Review of the pyrolysis platform for co-producing bio-oil and biochar. Biofuels, Bioproducts and Biorefining 3:547-562.

Lal, R. 2009. Soils and food sufficiency. A review. Agronomy and Sustainable Development 29:113-133.

Lal, R. 2020. Managing soils for negative feedback to climate change and positive impact on food and nutritional security. Soil Science and Plant Nutrition 66(1):1-9.
Lehmann, J., D.A. Bossio, I. Kögel-Knabner, and M.C. Rillig. 2020. The concept and future prospects of soil health. Nature Reviews Earth \& Environment 1:544-553.

Lehmann, J., J. Gaunt, and M. Rondon. 2006. Biochar sequestration in terrestrial ecosystems-A review. Mitigation and Adaptation Strategies for Global Change 11:403-427.

Lehmann, J., and S. Joseph, eds. 2015. Biochar for Environmental Management: Science, Technology and Implementation. New York: Routledge.

Li, W., J. Dumortier, H. Dokoohaki, F.E. Miguez, R.C. Brown, D. Laird and M.M Wright. 2019. Regional techno-economic and life-cycle analysis of the pyrolysis-bioenergy-biochar platform for carbon-negative energy. Biofuels, Bioproducts and Biorefining 13:1428-1438.

Man, K.Y., K.L. Chow,Y.B. Man, W.Y. Mo, and M.H. Wong. 2020. Use of biochar as feed supplements for animal farming. Critical Reviews in Environmental Science and Technology. https:// dx.doi.org/10.1080/10643389.2020.1721980.

Pecha, M.B., J.I. Montoya Arbelaez, M. Garcia-Perez, F. Chejne, and P. Ciesielski. 2019. Progress in understanding the four dominant intra-particle phenomena of lignocellulose pyrolysis: Chemical reactions, heat transfer, mass transfer, and phase change. Green Chemistry 21:2868.

Pollet, J., and P.N. Omi. 2002. Effect of thinning and prescribed burning on crown fire severity in ponderosa pine forests. International Journal of Wildland Fire 11:1-10.

Sahoo K., E. Bilek, R. Bergman, and S. Mani. 2019. Techno-economic analysis of producing solid biofuels and biochar from forest residues using portable systems. Applied Energy 235:578-590.

Sarauer J.L., D.S. Page-Dumroese, and M.D. Coleman. 2019. Soil greenhouse gas, carbon content, and tree growth response to biochar amendment in western United States forests. Global Change Biology-Bioenergy 11(5):660-671.

Schmidt, H.-P., N. Hagemann, K. Draper, and C. Kammann. 2019. The use of biochar in animal feeding. PeerJ 7:e7373.

Sessions J., D. Smith, K.M. Trippe, J.S. Fried, J.D. Bailey, J.H. Petitmermet, W. Hollamon, C.L. Phillips, and J.D. Campbell. 2019. Can biochar link forest restoration with commercial agriculture? Biomass and Bioenergy 123:175-185.

Smith, P. 2016. Soil carbon sequestration and biochar as negative emission technologies. Global Change Biology 22:1315-1324.

Smith, P., S.J. Davis, F. Creutzig, S. Fuss, J. Minx, B. Gabrielle, E. Kato, R.B. Jackson, A. Cowie, E. Kriegler, D.P. van Vuuren, J. Rogelj, P. Ciais, J. Milne, J.G. Canadell, D. McCollum, G. Peters,
R. Andrew, V. Krey, G. Shrestha, P. Friedlingstein, T. Gasser, A. Grübler, W.K. Heidug, M. Jonas, C.D. Jones, F. Kraxner, E. Littleton, J. Lowe, J.R. Moreira, N. Nakicenovic, M. Obersteiner, A. Patwardhan, M. Rogner, E. Rubin, A. Sharifi, A. Torvanger, Y. Yamagata, J. Edmonds, and C. Yongsung. 2015. Biophysical and economic limits to negative $\mathrm{CO}_{2}$ emissions. Nature Climate Change 6:42-50.

Spokas, K.A., K.B. Cantrell, J.M. Novak, D.W.Archer, J.A. Ippolito, H.P. Collins, A.A. Boateng, I.M. Lima, M.C. Lamb, A.J. McAloon, R.D. Lentz, and K.A. Nichols. 2012. Biochar: A synthesis of its agronomic impact beyond carbon sequestration. Journal of Environmental Quality 41:973-989.

Tammeorg, P., A.C. Bastos, S. Jeffery, F. Rees, J. Kern, E.R. Graber, M. Ventura, M. Kibblewhite, A. Amaro, A. Budai, C.M.d.S. Cordovil, X. Domene, C. Gardi, G. Gasco, J. Horák, C. Kammann, E. Kondrlova, D. Laird, S. Loureiro, M.A.S. Martins, P. Panzacchi, M. Prasad, M. Prodana, A.P. Puge, G. Ruysschaert, L. Sas-Paszt, F.C. Silva, W.G. Teixeira, G.Tonon, G. Delle Vedove, C. Zavalloni, B. Glaser, and F.G.A. Verheijen. 2017. Biochars in soils: Towards the required level of scientific understanding. Journal of Environmental Engineering and Landscape Management 25:192-207.

Woolf, D., J.E. Amonette, F.A. Street-Perrott, J. Lehmann, and S. Joseph. 2010. Sustainable biochar to mitigate global climate change. Nature Communications 1:56.

Woolf, D., J. Lehmann, E.M. Fisher, and L.T. Angenent. 2014. Biofuels from pyrolysis in perspective: Trade-offs between energy yields and soil-carbon additions. Environmental Science \& Technology 48:6492-6499.

Woolf, D., J. Lehmann, and D.R. Lee. 2016. Optimal bioenergy power generation for climate change mitigation with or without carbon sequestration. Nature Communications 7:13160.

Wu, P., S.T. Ata-Ul-Karim, B.P. Singh, H. Wang, T. Wu, C. Liu, G. Fang, D. Zhou, Y. Wang, and W. Chen. 2019. A scientometric review of biochar research in the past 20 years (1998-2018). Biochar 1:23-43. 